\title{
Studi Analisis Keandalan Sistem Distribusi 20 kV PT. PLN (Persero) UP3 Jambi ULP Kotabaru
}

\author{
Usep Zulkilpi ${ }^{1}$, Haerul Pathoni ${ }^{1}$, dan Dasrinal Tessal ${ }^{1}$ \\ ${ }^{1}$ Program Studi Teknik Elektro, Fakultas Sains dan Teknologi, Universitas Jambi, Indonesia \\ Email: zulkilpi9@gmail.com, haerul.pathoni@unja.ac.id, dasrinaltessal@unja.ac.id
}

\section{Info Artikel}

Diterima: 22 Juli 2021

Disetujui: 27 Agustus 2021

Dipublikasikan: 31 Agustus 2021

\section{Alamat Korespondensi: \\ zulkilpi9@gmail.com \\ Copyright (C) 2021 Jurnal \\ Engineering}

This work is licensed under the Creative Commons Attribution International License (CC BY 4.0).

\begin{abstract}
Abstrak
Kemajuan dalam bidang ilmu pengetahuan, teknologi dan pertumbuhan penduduk merupakan faktor yang menyebabkan permintaan energi listrik semakin meningkat. PT. PLN (Persero) sebagai perusahaan penyedia listrik terus berupaya untuk memenuhi semua permintaan energi listrik tersebut dengan pelayanan dalam sisi kualitas dan tingkat keandalan layanan yang tinggi. Untuk mengukur tingkat keandalan layanan ini dipakailah standar acuan SAIFI, SAIDI, dan CAIDI.

Nilai SAIDI, SAIFI, dan CAIDI didapatkan dengan mengumpulkan data jumlah gangguan, lamanya gangguan dan data pelanggan yang difokuskan pada ULP Kotabaru selama tahun 2019 sebelum dilakukan perhitungan berdasar persamaannya masing-masing.

Pada Unit Layanan Pelanggan Kotabaru tahun 2019 untuk nilai SAIDI sebesar 1,46 Jam/Pelanggan/Tahun, SAIFI sebesar 1,05 Kali/Pelanggan/Tahun dan CAIDI sebesar 1,46 Jam/Kali/Tahun. Standar IEEE nilai SAIDI 2,3 Jam/Pelanggan/Tahun, SAIFI 1,45 Kali/Pelanggan/Tahun dan CAIDI 1,47 Jam/Kali/Tahun. Sedangkan SPLN menetapkan 15,36 Jam/Pelanggan/Tahun, dan SAIFI 2,88 Kali/Pelanggan/Tahun. Hasil perhitungan keseluruhan hanya SAIDI yang tidak memenuhi standar IEEE akan tetapi memenuhi untuk standar SPLN dan dengan demikian tingkat keandalan sistem jaringan distribusi UP3 Jambi ULP Kotabaru dinyatakan handal.

Kata kunci: SAIDI, SAIFI, dan CAIDI
\end{abstract}

\section{Pendahuluan}

Energi listrik merupakan hal yang sangat penting dalam mendukung proses kehidupan masyarakat. Kemajuan dalam bidang ilmu pengetahuan, teknologi dan pertumbuhan penduduk merupakan faktor yang menyebabkan permintaan energi listrik semakin meningkat (Husna, Pelawi, \& Yusniati, 2017). Hal tersebut akan mengakibatkan bertambahnya kompleksitas sistem distribusi dan tingkat keandalannya semakin menurun dikarenakan pemadaman akan semakin sering terjadi baik sengaja maupun pemadaman yang terjadwal (pemeliharaan) (Hajar \& Pratama, 2018).

Dalam hal penyediaan energi listrik di Indonesia, PT. PLN (Persero) merupakan perusahaan yang berwenang untuk mengelolanya. Perusahaan listrik terbesar di Indonesia ini bergerak di bidang 
pendistribusian dan penyediaan energi listrik dengan seoptimal mungkin serta sejalan dengan peningkatan konsumen baik konsumen dalam skala kecil maupun dalam skala yang besar seperti industri dan lain-lain. PT. PLN (Persero) untuk pelayanan wilayah Provinsi Jambi, terdiri dari dua Unit Pusat Pelayanan Pelanggan (UP3), dimana masing-masing UP3 terbagi menjadi beberapa Unit Layanan Pelanggan (ULP) dengan rincian sebagai berikut :

a. UP3 Jambi : ULP Telanai Pura, ULP Kotabaru, ULP Seberang Kota, ULP Muara Bulian, ULP Kuala Tungkal, dan ULP Muara Sabak.

b. UP3 Muara Bungo : ULP Bungo Kota, ULP Bangko, ULP Sarolangun, ULP Muara Tebo, ULP Rimbo Bujang. (BPS Provinsi Jambi, 2019).

Untuk jumlah pelanggan yang berada di area UP3 Jambi dan UP3 Muara Bungo dari tahun 2016 sampai 2018 terjadi peningkatan jumlah pelanggan PLN sebesar 0,025\% setiap tahunnya. Masalah ini tentunya menjadi tugas serius bagi PT. PLN (Persero) dalam menuntaskan dan menyediakan energi listrik terkhusus di wilayah Provinsi Jambi.Selain terjadi peningkatan pelanggan, daya yang tersambung ke konsumen pada tiap-tiap unit pelayanan juga harus diperhatikan karena berkaitan dengan kepuasan konsumen atas mutu penyalurannya. Apabila kebutuhan daya listrik konsumen lebih besar dari pada yang tersedia, maka proses penyaluran tenaga listrik akan terganggu dan mengakibatkan pemadaman. Durasi pemadaman atau lamanya waktu pemadaman inilah yang dapat menjadi faktor menurunnya tingkat keandalan jaringan.

Dari latar belakang tersebut maka seharusnya dilakukan evaluasi terhadap keandalan layanan dari PLN terhadap meningkatnya jumlah pelanggan yang dilayaninya. Berdasarkan SAIFI, SAIDI, dan CAIDI dapat dilihat bagaimana kualitas layanan yang diberikan. Bila nilai SAIFI, SAIDI, dan CAIDI yang dihasilkan yang tidak memenuhi standar yang ditetapkan SPLN maka diperlukan tindakan lebih lanjut dengan menelaah persoalaannya secara mendetail seperti kualitas jaringan, ketersediaan daya, kemampuan peralatan, dll.

\section{Metode Penelitian}

Adapun jenis penelitian ini adalah bersifat kuantitatif yaitu penelitian yang digunakan untuk menjawab permasalahan melalui teknik pengukuran terhadap variabel-variabel tertentu, sehingga menghasilkan kesimpulan yang dapat di generalisasikan. Dalam penelitian ini melakukan analisis keandalan pelayanan sistem distribusi $20 \mathrm{kv}$ dengan menghitung gangguan yang terjadi yang terdiri dari durasi terjadinya gangguan, berapa banyaknya gangguan dalam satuan waktu tertentu, dan banyaknya pelanggan yang dilayani serta banyaknya pelanggan yang mengalami gangguan. Nantinya data tersebut akan dihitung dengan menggunakan perhitungan SAIDI, SAIFI dan CAIDI untuk selanjutnya dibandingkan dengan Standar SPLN dan IEEE.

Penelitian dilaksanakan selama 5 bulan, dimulai pada Desember 2019 hingga Maret 2020. Penelitian dilaksanakan di jaringan distribusi $20 \mathrm{kV}$ yang terletak pada PLN Wilayah Sumatera Selatan, Jambi dan Bengkulu (WS2JB) Unit Pusat Pelayanan Pelanggan (UP3) Jambi Unit Layanan Pelanggan (ULP) Kota Baru dan adapun kantor ULP Kota Baru berlokasi di Jl. Nuri I, Kel. Jelutung, Kec. Jelutung, Kota Jambi. Tahapan penelitian yang dilakukan pada penelitian ini berdasarkan diagram alir (flowchart) pada Gambar 1. 


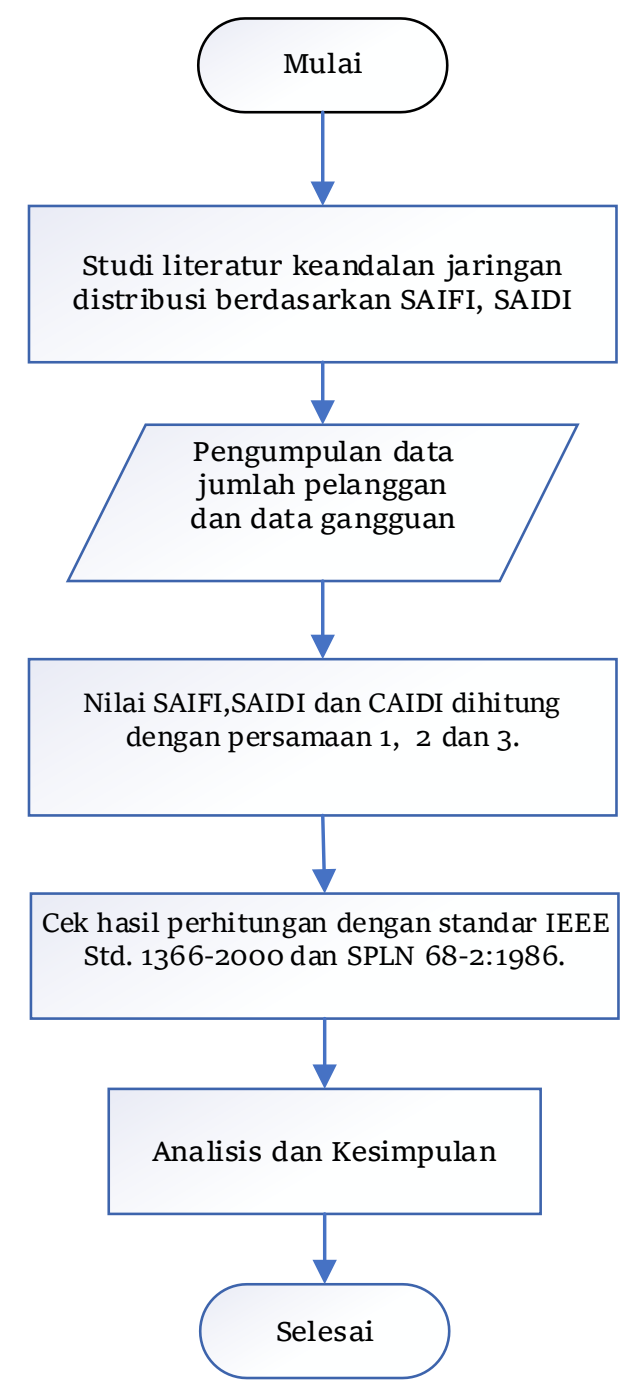

Gambar 1. Tahapan Kerja

a. SAIDI( System Average interruption Duration Index)

SAIDI didefinisikan sebagai nilai rata-rata dari lamanya gangguan untuk setiap konsumen selama periode waktu tertentu(Perdana, Hasanah, \& Dachlan, 2009). nilai ini ditampilkan pada persamaan 1.

$S A I D I=\frac{\frac{\sum U i N i}{\sum \lambda i}}{\sum N i}(\mathrm{jam} /$ pelanggan $/$ tahun $)$

Dimana :

$\Sigma U \quad$ : Durasi pemadaman

$\mathrm{Ni}$ : Pelanggan yang mengalami pemadaman

$\Sigma \mathrm{Ni} \quad$ : Total pelanggan yang dilayani

$\Sigma \lambda_{\mathrm{i}} \quad$ : Total frekuensi pemadaman

b. SAIFI (System Average Interruption Frequency Index) 
SAIFI adalah indeks keandalan yang merupakan jumlah dari perkalian frekuensi padam dan pelanggan padam dibagi dengan jumlah pelanggan yang dilayani (Saodah, 2008). Untuk menghitung SAIFI menggunakan persamaan 2.

$$
S A I F I=\frac{\frac{\sum \lambda i N i}{\sum \lambda i}}{\sum N i}(\mathrm{kali} / \text { pelanggan } / \text { tahun })
$$

Dengan :

$\Sigma \lambda \mathrm{i} \quad$ : Total frekuensi padam

$\mathrm{Ni} \quad$ : Pelanggan yang mengalami pemadaman

$\Sigma \mathrm{Ni} \quad$ : Jumlah pelanggan total yang dilayani

c. CAIDI (Customer Average Interruption Duration Index)

CAIDI adalah indeks durasi gangguan konsumen rata-rata tiap periode waktu tertentu, menginformasikan waktu rata-rata untuk penormalan kembali gangguan tiap-tiap pelanggan dalam satu tahun (Goenadi, 2012). Untuk menghitung CAIDI menggunakan persamaan 3.

$$
C A I D I=\frac{S A I D I}{S A I F I}(\mathrm{jam} / \mathrm{kali} / \mathrm{tahun})
$$

d. Parameter Standar Indeks Keandalan

1) Standar Indeks Keandalan SPLN 68-2:1986.

Adapun standar SAIDI dan SAIFI ditetapkan oleh PT. PLN (Persero) terdapat pada buku standar perusahaan umum listrik mengenai tingkat jaminan sistem energi listrik bagian dua sistem distribusi atau lebih dikenal dengan sebutan SPLN 68-2:1986. Standar yang digunakan untuk menentukan SAIDI dan SAIFI telah dituliskan dalam SPLN 68-2:1986 seperti pada Tabel 1.

Tabel. 1 Parameter Indeks Keandalan Pelayanan (Sumber : SPLN:1986)

\begin{tabular}{ccc}
\hline Indeks Keandalan & Standar Nilai & Satuan \\
\hline SAIFI & 2,88 & Kali/Pelanggan/Tahun \\
SAIDI & 15,36 & Jam/Pelanggan/Tahun \\
\hline
\end{tabular}

2) Standar Indeks Keandalan IEEE Std $1366^{\mathrm{TM}}-2003$

Adapun standar SAIDI, SAIFI dan CAIDI ditetapkan oleh Institute of Electrical and Electronic Engineers (IEEE) bagian Guide for Electric Power Distribution Reliability Indices. Standar yang digunakan untuk menentukan SAIDI dan SAIFI tertera pada Tabel 2.

Tabel 2. Standar Indeks Keandalan IEEE Std $1366^{\text {TM }}-2003$ (Sumber IEEE : 2003)

\begin{tabular}{ccc}
\hline Indikator Keandalan & Standar Nilai & Satuan \\
\hline SAIFI & 1,45 & Kali/Pelanggan/Tahun \\
SAIDI & 2,30 & Jam/Pelanggan/Tahun \\
CAIDI & 1,47 & Jam/Kali/Tahun \\
\hline
\end{tabular}




\section{Hasil Perhitungan dan Pembahasan}

a. Hasil Perhitungan

Dalam melakukan perhitungan System Average Duration Indeks (SAIDI), System Average Frekuension Indeks (SAIFI), dan Customer Average Duration Indeks (CAIDI) dilakukan per bulan berdasarkan data yang diperoleh dari PT. PLN (Persero) Unit Layanan Pelanggan Kotabaru. Adapun data yang akan dihitung dimulai dari bulan Januari 2019 sampai dengan Desember 2019, dalam perhitungan ini dilakukan dengan cara perhitungan secara manual. Berikut hasil perhitungan SAIDI, SAIFI dan CAIDI selama tahun 2019.

Tabel3 . Rekapitulasi Nilai Hasil Perhitungan

(Sumber : PT. PLN (Persero) ULP KotaBaru)

\begin{tabular}{|c|c|c|c|c|}
\hline $\mathrm{NO}$ & BULAN & SAIDI & SAIFI & CAIDI \\
\hline 1 & Januari & 1,51 & 1,36 & 1,11 \\
\hline 2 & Februari & 1,72 & 0,91 & 1,89 \\
\hline 3 & Maret & 1,20 & 1,04 & 1,15 \\
\hline 4 & April & 1,63 & 1,38 & 1,18 \\
\hline 5 & Mei & 0,98 & 1,22 & 0,80 \\
\hline 6 & Juni & 1,01 & 1,23 & 0,82 \\
\hline 7 & Juli & 1,66 & 0,95 & 1,75 \\
\hline 8 & Agustus & 0,97 & 0,52 & 1,87 \\
\hline 9 & September & 1,79 & 1,13 & 1,58 \\
\hline 10 & Oktober & 1,49 & 0,86 & 1,73 \\
\hline 11 & November & 1,71 & 0,84 & 2,04 \\
\hline \multirow[t]{2}{*}{12} & Desember & 1,87 & 1,18 & 1,58 \\
\hline & Jumlah & 17,54 & 12,62 & 17,50 \\
\hline & $\begin{array}{c}\text { Rata-rata Nilai } \\
\text { (dalam satu tahun) }\end{array}$ & 1,46 & 1,05 & 1,46 \\
\hline
\end{tabular}

Dari Tabel 3 diatas dapat dilihat dalam bentuk grafik pada Gambar 2. Gambar 2 memperlihatkan hasil perhitungan SAIDI, SAIFI dan CAIDI selama satu tahun terhitung dari Januari 2019 sampai Desember 2019. Gambar 2 memperlihatkan naik dan turunnya nilai SAIFI, SAIDI, dan CAIDI selama tahun 2019.

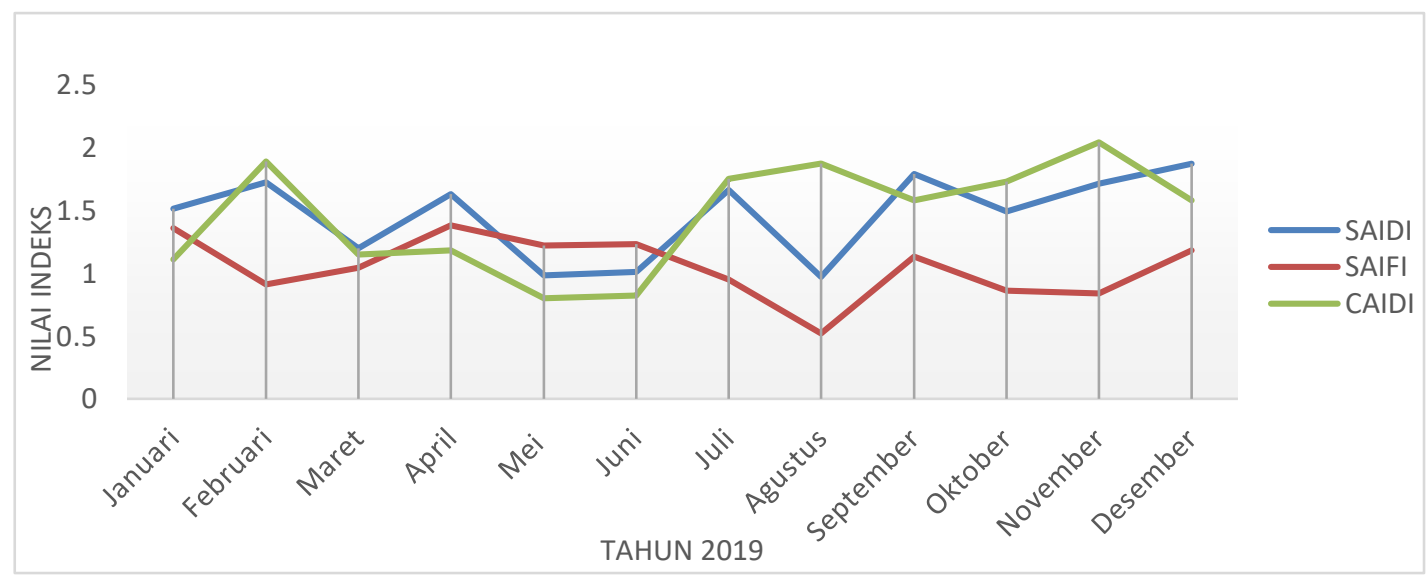

Gambar 2. Grafik Nilai Hasil Perhitungan SAIDI, SAIFI dan CAIDI 
b. Perbandingan hasil perhitungan

Tabel 4. Perbandingan Hasil Perhitungan dengan Parameter Indeks Keandalan

\begin{tabular}{cccccc}
\hline \multirow{2}{*}{ NO } & \multirow{2}{*}{$\begin{array}{c}\text { Indikator } \\
\text { Penilaian }\end{array}$} & Hasil & \multicolumn{2}{c}{ Standar Indeks } & Serhitungan \\
& & & \multicolumn{2}{c}{ Keandalan } & Satuan \\
\hline 1 & SAIDI & 1,46 & 1,45 & 15,36 & Jam/Pelanggan/Tahun \\
2 & SAIFI & 1,05 & 2,30 & 2,88 & Kali/Pelanggan/Tahun \\
3 & CAIDI & 1,46 & 1,47 & - & Jam/Kali/Tahun \\
\hline
\end{tabular}

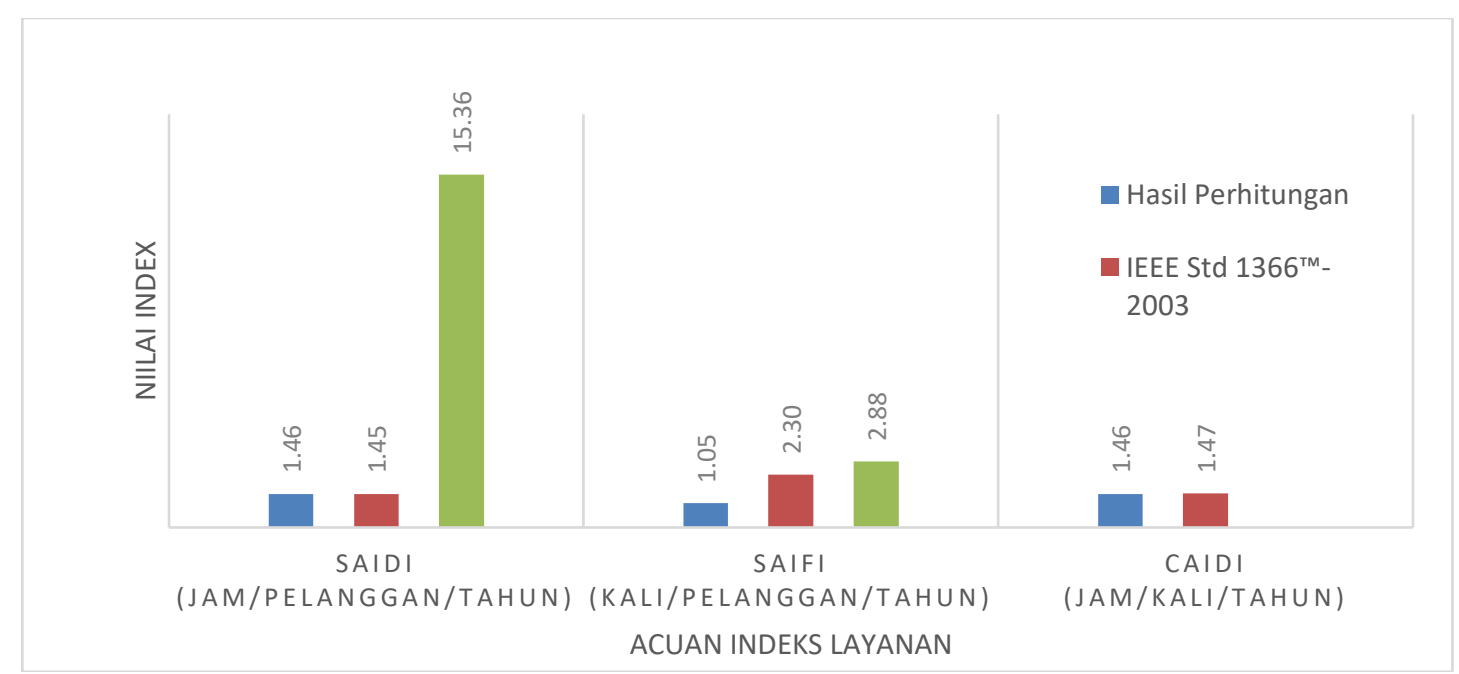

Gambar 3. Grafik Perbandingan Hasil Perhitungan Dengan Parameter Indeks Keandalan

c. Analisis data hasil perhitungan

Berdasarkan Tabel 3 dan Gambar 2 hasil rekapitulasi nilai SAIDI mengalami kenaikan dan penurunan hal ini terjadi karena durasi gangguan dan jumlah pelanggan yang mengalami gangguan dan total pelanggan yang dilayani berbeda tiap bulannya. Hasil perhitungan nilai SAIDI pada tahun 2019 yang tertera pada Tabel 4 sebesar 1,46 Jam/Pelanggan/Tahun berdasarkan standar IEEE tingkat keandalannya tidak baik karena melampaui standar maksimum namun berdasarkan standar SPLN tingkat keandalannya baik karena memenuhi standar nilai maksimum yaitu 15,36 Jam/Pelanggan/Tahun, perbandingan ini dapat dilihat pada Gambar 3. Berdasarkan data SAIDI dapat dinyatakan apabila durasi gangguan lama, jumlah pelanggan yang mengalami pemadaman besar namun frekuensi dan total pelanggan yang dilayani kecil sehingga nilai SAIDI semakin besar namun jika jumlah pelanggan yang terkena pemadaman besar namun frekuensi dan total pelanggan yang dilayani besar maka nilai SAIDI semakin kecil.

Perbedaan yang sangat jauh antara nilai perhitungan SAIDI dengan standar nilai indeks keandalan sistem SPLN dikarenakan untuk wilayah Sumatera sendiri memiliki tingkat jaminan sebesar 1,2 dimana lebih besar dari standar indeks yang ada di DKI Jakarta dan Tangerang. Untuk SAIDI di wilayah DKI Jakarta dan Tangerang memiliki nilai indeks keandalan sebesar 12,8 Jam/tahun, dikali dengan tingkat jaminan wilayah sumatera sebesar 1,2 maka didapat nilai 15,36 Jam/tahun. Nilai standar indeks keandalan untuk durasi gangguan pada buku SPLN tahun 1986 sangat tinggi dibanding standar IEEE karena standar SPLN telah disesuaikan dengan target PLN yang berfokus pada pengembangan serta perluasan jaringan 
distribusi agar bisa menjangkau masyarakat secara keseluruhan. Hal demikian bukan berarti PLN mengesampingkan kualitas pelayanan, PLN tetap mengembangkan jangkauan pelayanan dengan memperhatikan kualitas pelayanannya dan hal ini terbukti dengan modernisasi peralatan distribusi untuk meminimalisir gangguan.

Berdasarkan Tabel 3 dan Gambar 2 hasil Rekapitulasi nilai SAIFI terjadi kenaikan dan penurunan hal ini terjadi karena durasi ganguan dan jumlah pelanggan yang mengalami gangguan dan total pelanggan yang dilayani berbeda tiap bulannya. Hasil perhitungan nilai SAIFI pada tahun 2019 yang ditampilkan pada Tabel 4 sebesar 1,05 Kali/Pelanggan/Tahun sehingga dapat dinyatakan bahwa tingkat keandalannya baik karena telah memenuhi standar IEEE yaitu 1,45 Kali/Pelanggan/Tahun dan SPLN 2,88 Kali/Pelanggan/Tahun (Gambar 3). Apabila jumlah pelanggan yang mengalami pemadaman lebih besar dari jumlah pelanggan total kecil maka nilai SAIFI yang dihasilkan akan semakin besar dan apabila Jumlah pelanggan yang mengalami gangguan lebih kecil dari jumlah pelanggan total maka nilai SAIFI yang dihasilkan semakin kecil.

Berdasarkan Tabel 3 dan Gambar 2 hasil Rekapitulasi nilai CAIDI terjadi kenaikan dan penurunan, nilai CAIDI yang diperoleh tergantung pada besar dan kecilnya nilai SAIDI dan SAIFI pada bulan tersebut. Hasil perhitungan nilai CAIDI pada tahun 2019 sebesar 1,46 Jam/Kali/Tahun dapat dinyatakan bahwa tingkat keandalannya baik karena telah memenuhi standar maksimum IEEE yaitu 1,47 Jam/Kali/Tahun (Gambar 3).

\section{Kesimpulan}

Dari hasil perhitungan dan pembahasan System Avarage Iterruption Duration Index (SAIDI), System Avarage Interruption Frequency Index (SAIFI) dan Customer Average Interruption Duration Index (CAIDI) maka dapat diberikan kesimpulan sebagai berikut :

a. Berdasarkan hasil perhitungan dalam rentan waktu satu tahun didapat hasil sebagai berikut : untuk nilai SAIDI yang didapatkan sebesar 1,46 Jam/Pelanggan/Tahun, nilai SAIFI yang didapatkan sebesar 1,05 Kali/Pelanggan/Tahun, dan nilai CAIDI yang didapatkan sebesar 1,46 Jam/Kali/Tahun.

b. Berdasar hasil perhitungan nilai SAIDI, SAIFI, dan CAIDI, nilai dari ketiganya memenuhi parameter standar SPLN. Sedangkan untuk parameter standar nilai IEEE hanya nilai SAIDI yang tidak layak, hal ini disebabkan oleh durasi pemadaman terlalu lama mulai dari mulai terjadinya gangguan sampai dengan proses penormalan kembali.

\section{Daftar Pustaka}

[1] BPS Provinsi Jambi. (2019). Jambi Dalam Angka 2019. Kota Jambi: Badan Pusat Statistik Provinsi Jambi.

[2] D. R. Indices. (2004). IEEE Guide for Electric Power Distribution Reliability Indices," in IEEE Std 1366-2012 (Revision of IEEE Std 1366-2003) , vol., no., pp.1-43, 31 May 2012 doi: 10.1109/IEEESTD.2012.6209381,. Vol. 2003.

[3] Departemen Pertambangan dan Energi PT. PLN (Persero). (1986). SPLN Tingkat Jaminan Sistem Distribusi Tenaga Listrik. Jakarta.

[4] Goenadi, C. (2012). Analisis keandalan sistem jaringan Distribusi $20 \mathrm{kV}$ di PT PLN distribusi Jawa Timur Kediri dengan metode simulasi Section Technique. Jurnal Teknik Pomits , 1-6. 
[5] Hajar, I., \& Pratama, M. H. (2018). Tenaga Listrik Pada Penyulang Cahaya Pt. Pln (Persero) Area Ciputat. STT. PLN.

[6] Husna, J., Pelawi, Z., \& Yusniati. (2017). Saluran Udara Tegangan Menengah Di Pt. Pln Wilayah Nad Cabang Langsa. Buletin Utama Teknik Vol. 14, no. 1, 13-17.

[7] Perdana, W. P., Hasanah, R. N., \& Dachlan, H. S. (2009). Evaluasi Keandalan Sistem Tenaga Listrik Pada Jaringan Distribusi Primer Tipe Radial Gardu Induk Blimbingan. EECCIS Vol. III, 6.

[8] PT. PLN (Persero) SPLN 59 . (1985). Keandalan Pada Sistem Distribusi $20 \mathrm{kV}$ dan 6 kV. Jakarta: Departemen Pertambangan dan Energi Perusahaan Umum Listrik Negara.

[9] Saodah, S. (2008). Evaluasi Keandalan Sistem Distribusi Tenaga Listrik Berdasarkan SAIDI dan SAIFI. Yogjakarta: Institut Teknologi Nasional. 